\title{
Dubowitz syndrome: common findings and peculiar urine odor
}

This article was published in the following Dove Press journal:

The Application of Clinical Genetics

7 October 2013

Number of times this article has been viewed

\section{Cynthia Chehade' \\ Johnny Awwad ${ }^{2}$ \\ Nadine Yazbeck' \\ Marianne Majdalani' \\ Rima Wakim' \\ Hala Tfayli' \\ Chantal Farral,3}

'Department of Pediatrics and Adolescent Medicine, American University of Beirut Medical Center, Beirut, Lebanon; ${ }^{2}$ Department of Obstetrics and Gynecology, American University of Beirut Medical Center, Beirut, Lebanon; ${ }^{3}$ Department of Pathology and Laboratory Medicine, American University of Beirut Medical Center, Beirut, Lebanon
Correspondence: Chantal Farra Department of Pediatrics and Adolescent Medicine, American University of Beirut Medical Center, PO Box II-0236, Riad El Solh II 07 2020, Beirut, Lebanon

Tel +96 I I 350000 ext.5427

Fax+96। I 370845

Email cf07@aub.edu.lb
Background: Dubowitz syndrome is a rare, autosomal recessive disorder characterized by intrauterine and postnatal growth retardation, severe microcephaly, psychomotor retardation, hyperactivity, eczema, and characteristic dysmorphic facial features. Although many cases have been reported, the cause of this disease is still unknown.

Case: We present here the case of a Lebanese girl with Dubowitz syndrome in whom an unpleasant urine odor was persistently reported since birth.

Conclusion: Although Dubowitz syndrome has been largely described in the medical literature, this is the first time that a peculiar urine odor was reported. This case report adds a new and unusual feature to the numerous findings related to this rare polymorphous syndrome.

Keywords: Dubowitz syndrome, autosomal recessive, developmental delay, odorous urine

\section{Introduction}

Dubowitz syndrome is a condition characterized by multiple congenital anomalies. ${ }^{1}$ It is described as a rare autosomal recessive disorder with a unique set of clinical features, including microcephaly, short stature, broad nasal bridge, sloping forehead and micrognathia, facial asymmetry, blepharophimosis, sparse hair and eyebrows, low-set ears, growth and mental retardation, and susceptibility to tumor formation. Children with this syndrome have similar behavioral characteristics. Hyperactivity, minimal attention, aggressiveness, shyness, dislike of crowds, food refusal, and bedwetting have all been reported. In addition, Dubowitz syndrome is known to be associated with other medical problems that increase the risk for a shorter life span. Although Dubowitz syndrome has been well described in the literature since it was first identified in 1965, the exact cause of this disorder is still unknown and diagnosis is based mainly on clinical features..$^{2-5}$

Here, we report the case of a girl having typical features of Dubowitz syndrome (facial dysmorphism, eczema, microcephaly, and developmental and growth delay), with an unexplained odorous urine that has never been reported to be associated with the syndrome.

\section{Case presentation}

A 5-year-old girl was presented to our institution because of failure to thrive. She was the fifth child of unrelated parents originating from the same village in the south of Lebanon. She was born vaginally at term to a 33-year-old mother; her birth weight was 2,200 grams. The course of pregnancy was normal and the mother denied any medication use, smoking, or alcohol intake. The girl's perinatal history was significant 
for neonatal jaundice requiring phototherapy. The family history was unremarkable except for mental retardation in a maternal uncle and a congenital heart defect in an older brother.

In early infancy, the girl had feeding difficulties and failed to thrive. She also had a history of recurrent respiratory infections and eczematous skin changes. In addition, since birth she had had a musty urine odor that had never been reported in her family. Urine analyses were repeatedly normal.

At consultation, developmental evaluation revealed a hyperactive child with significant speech delay. Her vocabulary consisted of 10-15 words. She used few two-word sentences. Otherwise, the gross and fine motor abilities were adequate for her age. She made good eye contact and could understand and carry out simple verbal instructions, but she had a short attention span and impulsive behavior.

Upon examination, her height was reported at $84 \mathrm{~cm}$, her weight was $10 \mathrm{~kg}$, and her head circumference was $44 \mathrm{~cm}$, all below the third percentile according to US Centers for Disease Control growth charts. ${ }^{6}$

She had fair, dry skin and sparse, fine blond hair. Her face was elongated with a high sloping forehead. She had sparse lateral eyebrows, long eyelashes, wide-set eyes (telecanthus) with hypertelorism, low-set ears, a broad nasal bridge with a prominent tip, micrognathia, a thin upper lip, a high-arched palate, dental caries, a sacral dimple, and eczematous skin changes on the extremities, mainly on the flexural areas (Figures 1 and 2).

When she smiled, her facial skin wrinkled and she looked like a prematurely aged girl (Figure 3 ). The remainder of the physical examination was normal.

Laboratory workup yielded normal results for the following tests: complete blood count, serum blood urea nitrogen, creatinine, sodium, potassium, chloride, total serum protein, liver function, lipid profile, thyroid hormone, urine organic acids, plasma acylcarnitine profile and free carnitine level, plasma amino acids, serum lactate and pyruvate levels, plasma zinc, plasma immunoglobulins including normal immunoglobulin E levels, urinalysis, urine cultures, stool studies, insulin-like growth factor 1 , antiendomyseal antibodies, sweat chloride, and 46,XX karyotype.

Other tests included MRI examination of the brain, X-rays of the spine, a voiding cystourethrogram, and an upper gastrointestinal series; all were normal. An echocardiography revealed a trace mitral regurgitation. Bone age was 2-years delayed compared with the chronological age.

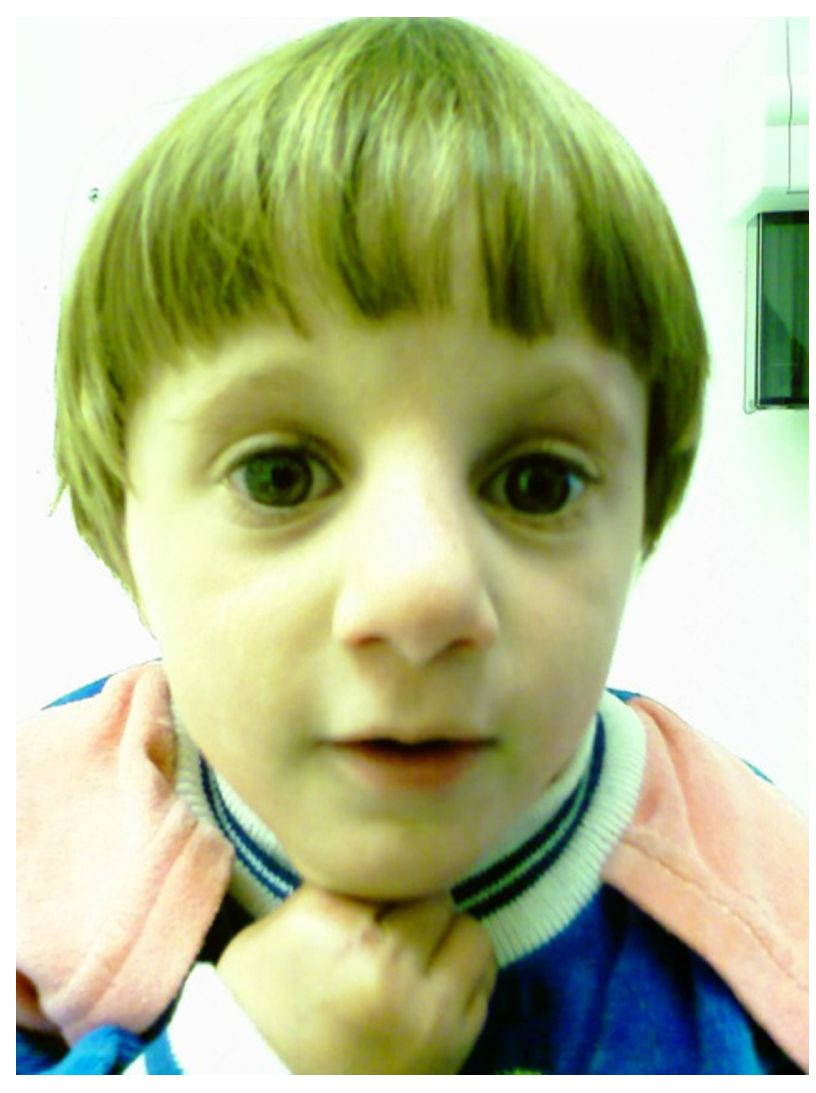

Figure I High forehead with flat supraorbital ridges and widely spaced eyes.

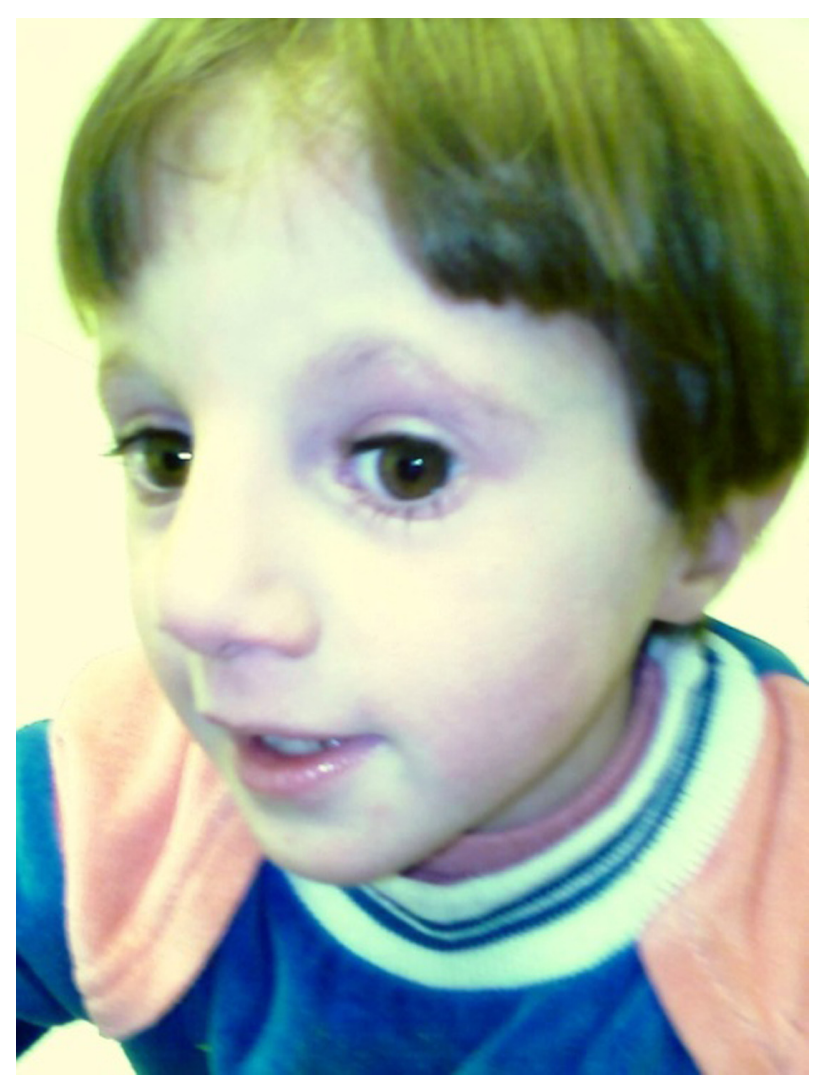

Figure 2 Prominent nasal bridge and sparse eyebrows. 


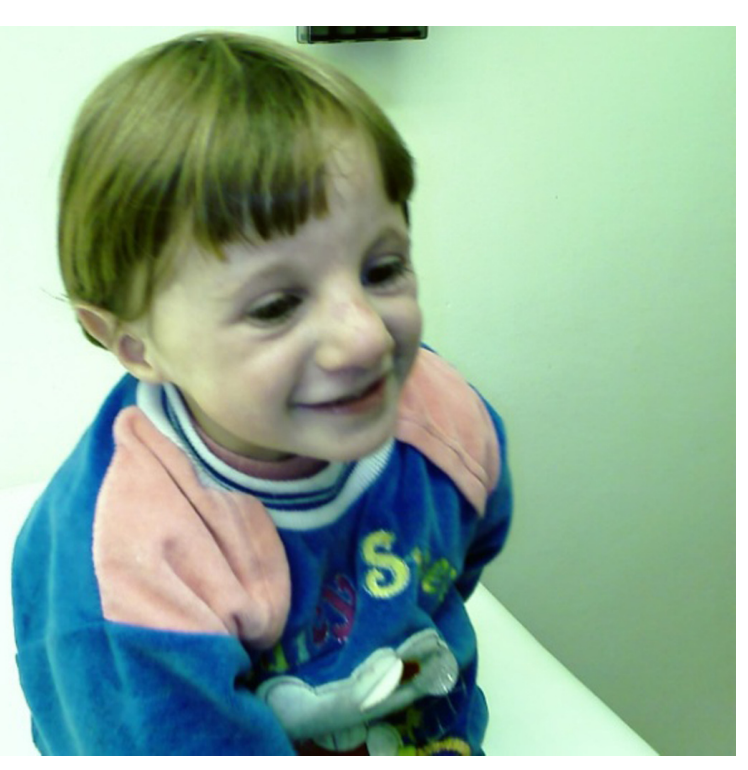

Figure 3 Prematurely aged appearance of the proband when she smiles.

\section{Discussion}

This case report presents a patient with Dubowitz syndrome. This is the first case reported from Lebanon. Although direct consanguinity has been reported in a number of cases, ${ }^{7-9}$ Dubowitz syndrome is underreported in the Arab population, which is known to have a high consanguinity rate. ${ }^{7}$

Dubowitz syndrome is a very rare childhood disorder. The direct cause of the disorder is still unknown; however, most of the published data refer to possible genetic etiology. ${ }^{2}$ Indeed, a recent study has reported the NSUN2 gene as the first potential causal gene with a relationship to the Dubowitz syndrome spectrum phenotype. ${ }^{10}$

So far, diagnosis of Dubowitz syndrome is reached primarily through observational methods, mainly based on examination of facial appearance, growth records, and medical history. ${ }^{2,3}$ Although most reported cases in the literature share the classic characteristics that define this syndrome, ${ }^{2,3,5}$ it is still difficult to diagnose the disorder as many of the features may not be prominent or concordant in different cases. In addition, Dubowitz syndrome shares symptoms of mental and growth retardation, chromosomal instability, and skin lesions with other disorders such as Bloom syndrome, Fanconi anemia, and fetal alcohol syndrome, ${ }^{2-4}$ suggesting that Dubowitz syndrome can easily be confused with these other disorders and thus easily underdiagnosed or misreported.

The main feature that distinguishes Dubowitz syndrome from Bloom syndrome and Fanconi anemia is facial appearance. ${ }^{11}$ On the other hand, fetal alcohol syndrome may present with comparable facial features, as well as microcephaly, hyperactivity, growth and mental retardation - all of which can be present in Dubowitz syndrome. ${ }^{5,9}$ However, absence of prenatal alcohol exposure in this case definitely rules out fetal alcohol syndrome..$^{2-4,11}$

Our patient had the classic clinical findings of Dubowitz syndrome; however, a new finding stands out in our case: the presence of an unpleasant urine odor. To our knowledge, this case report is the first to describe this condition in a patient with Dubowitz syndrome. Odorous urine can be the result of dehydration, urinary infection, or various metabolic etiologies. ${ }^{12}$ An odor of burnt sugar or maple syrup is characteristic of maple syrup urine disease, a sweaty-feet odor can be found in isovaleric acidemia, a cat-like odor is associated with multiple carboxylase deficiency and 3-methylcrotonylglycinuria, and a cabbage-like odor is found in tyrosinemia and methionine malabsorption. ${ }^{13}$

In our patient, infectious and metabolic causes have been ruled out. Previous case reports have suggested that Dubowitz syndrome is a result of a certain cholesterol metabolism disorder that is reflected in a low lipoprotein profile. ${ }^{14,15}$ However, the lipid profile of our patient was normal. One main differential diagnosis resulting from eczematous dermatitis and a musty or mousey odor of urine in children is phenylketonuria, ${ }^{13}$ and this condition was ruled out as well. Odorous urine may be reportedly the result of certain medications. However, our patient did not report intake of any drugs. ${ }^{16}$

Although Dubowitz syndrome has been thoroughly described in the medical literature, this is the first time that a peculiar urine odor has been reported. Given the rarity and thus the relatively limited data on the condition, this finding should not be disdained and, until proven otherwise, we cautiously conclude that odorous urine may be a new feature to add to the clinical presentation of Dubowitz syndrome. More data and descriptive presentation are required to improve the diagnosis and the quality of care for individuals with Dubowitz syndrome.

\section{Acknowledgments}

Parental consent has been obtained for the use of patient photos.

\section{Disclosure}

The authors report no conflicts of interest in this work.

\section{References}

1. Darcy DC, Rosenthal S, Wallerstein RJ. Chromosome deletion of 14q32.33 detected by array comparative genomic hybridization in a patient with features of dubowitz syndrome. Case Rep Genet. 2011; 2011:306072. 
2. Huber RS, Houlihan D, Filter K. Dubowitz syndrome: a review and implications for cognitive, behavioral, and psychological features. J Clin Med Res. 2011;3(4):147-155.

3. Pascual JC, Betlloch I, Bañuls J, Vergara, G. What syndrome is this? Dubowitz syndrome. Pediatr Dermatol. 2005;22(5):480-481.

4. Tsukahara M, Opitz JM. Dubowitz syndrome: review of 141 cases including 36 previously unreported patients. Am J Med Genet. 1996;63(1): 277-289.

5. Yue J, Lu H, Lan S, et al. Identification of the DNA repair defects in a case of Dubowitz syndrome. PLoS ONE. 2013;8(1):e54389.

6. Clinical Growth Charts. Centers of Disease Control and Prevention. Available from: http://www.cdc.gov/growthcharts/clinical_charts. Accessed July 7, 2013.

7. Al-Nemri AR, Kilani RA, Salih MA, Al-Ajlan AA. Embryonal rhabdomyosarcoma and chromosomal breakage in a newborn infant with possible Dubowitz syndrome. Am J Med Genet. 2000;92(2): 107-110.

8. Dubowitz V. Familial low birthweight dwarfism with an unusual facies and a skin eruption. J Med Genet. 1965;2(1):12-17.

9. Vieluf D, Korting HC, Braun-Falco O, Walther JU. Dubowitz syndrome: atopic dermatitis, low birth weight dwarfism and facial dysmorphism. Dermatologica. 1990;180(4):247-249.
10. Martinez FJ, Lee JH, Lee JE, et al. Whole exome sequencing identifies a splicing mutation in NSUN2 as a cause of a Dubowitz-like syndrome. J Med Genet. 2012;49(6):380-385.

11. Sunku AJ, Gomez MR, Klass DW. Epileptic seizures, EEG abnormalities, and neuronal heterotopia in the Dubowitz syndrome. Am J Electroneurodiagnostic Technol. 1998;38(3):156-163.

12. Struthers S, Scanlon J, Parker K, Goddard J, Hallett R. Parental reporting of smelly urine and urinary tract infection. Arch Dis Child. 2003;88(3):250-252.

13. Enns GM, Packman S. Diagnosing inborn errors of metabolism in the newborn: clinical features. NeoReviews. 2001;2(8):e183-e191.

14. Yeşilkaya E, Karaer K, Bideci A, Camurdan O, Perçin EF, Cinaz P. Dubowitz syndrome: a cholesterol metabolism disorder? Genet Couns. 2008;19(3):287-290.

15. Ahmad A, Amalfitano A, Chen YT, Kishnani PS, Miller C, Kelley R. Dubowitz syndrome: a defect in the cholesterol biosynthetic pathway? Am J Med Genet. 1999;86(5):503-504.

16. Harvard Medical School. Urine Color and Odor Changes. Harvard Women's Health Watch. Cambridge, MA: Harvard University; 2010; Available from: http://www.health.harvard.edu/newsletters/Harvard_ Womens_Health_Watch/2010/June/urine-color-and-odor-changes. Accessed July 7, 2013.
The Application of Clinical Genetics

\section{Publish your work in this journal}

The Application of Clinical Genetics is an international, peer-reviewed open access journal that welcomes laboratory and clinical findings in the field of human genetics. Specific topics include: Population genetics; Functional genetics; Natural history of genetic disease; Management of genetic disease; Mechanisms of genetic disease; Counseling and ethical

\section{Dovepress}

issues; Animal models; Pharmacogenetics; Prenatal diagnosis; Dysmorphology. The manuscript management system is completely online and includes a very quick and fair peer-review system, which is all easy to use. Visit http://www.dovepress.com/testimonials.php to read real quotes from published authors.

Submit your manuscript here: http://www.dovepress.com/the-application-of-clinical-genetics-journal 